\title{
Three symbol ungrounding problems: Abstract concepts and the future of embodied cognition
}

\author{
Guy Dove ${ }^{1}$
}

Published online: 2 April 2015

(C) Psychonomic Society, Inc. 2015

\begin{abstract}
A great deal of research has focused on the question of whether or not concepts are embodied as a rule. Supporters of embodiment have pointed to studies that implicate affective and sensorimotor systems in cognitive tasks, while critics of embodiment have offered nonembodied explanations of these results and pointed to studies that implicate amodal systems. Abstract concepts have tended to be viewed as an important test case in this polemical debate. This essay argues that we need to move beyond a pretheoretical notion of abstraction. Against the background of current research and theory, abstract concepts do not pose a single, unified problem for embodied cognition but, instead, three distinct problems: the problem of generalization, the problem of flexibility, and the problem of disembodiment. Identifying these problems provides a conceptual framework for critically evaluating, and perhaps improving upon, recent theoretical proposals.
\end{abstract}

Keywords Semantic memory · Concepts .

Embodied cognition · Word meaning · Grounded cognition

For a long time, the orthodoxy within cognitive science held that the human conceptual system was functionally distinct from the perception, action, and emotion systems. Conceptual knowledge was encoded in amodal symbols (i.e., representations that are not indigenous to any particular sensorimotor or affective modality). In the past decade and a half, though, the idea that concepts are in some significant sense grounded in the brain mechanisms used to experience the world has gained

Guy Dove

guy.dove@louisville.edu

1 Department of Philosophy, University of Louisville, 313B Humanities Building, Louisville, KY 40208, USA a great deal of currency. An important impetus for this shift has been the emergence of an ever-increasing body of evidence implicating perception, action, and emotion systems in conceptual tasks (for reviews, see Fischer \& Zwaan, 2008; Kemmerer, 2010; Kiefer \& Pulvermüller, 2012). This has led to the development of an embodied view of concepts in which affective and sensorimotor representations play a central role (Barsalou, 1999, 2008; Gallese \& Lakoff, 2005).

Our facility with abstract concepts such as ANIMAL, DEMOCRACY, ODD NUMBER, ELECTRON, and TRUT $\mathrm{H}$ poses a serious challenge to this view (Chatterjee, 2010; Dove, 2009; Mahon \& Caramazza, 2008; Weiskopf, 2007). When this problem first emerged, many skeptics of embodied cognition observed that most of the proffered evidence involved concrete concepts. With time, though, the issues raised by abstract concepts have become more complicated. First, more research from an embodied and grounded perspective has been carried out on abstract concepts (e.g., Barsalou \& Wiemer-Hastings, 2005; Borghi \& Binkofski, 2014; Glenberg et al., 2008; Kousta, Vigliocco, Vinson, Andrews, \& Del Campo, 2011; Scorolli et al., 2011; Scorolli et al., 2012; Vigliocco et al., 2014; Watson, Cardillo, Ianni, \& Chatterjee, 2013). Second, there is a growing consensus that some kind of hybrid account - based on such dichotomies as modal/ amodal, embodied/disembodied, and so forth-is needed (e.g., Dove, 2009, 2011; Pulvermüller \& Garagnani, 2014; Reilly et al., 2014; Shallice \& Cooper, 2013; Watson \& Chatterjee, 2011; Zwaan, 2014). Both of these factors suggest that now is the right time to reexamine abstract concepts. My aim in this essay is to show that, when viewed against the background of current research and theory, they do not pose a cohesive, unitary problem for embodied cognition (see also Barsalou, 2010). In particular, I contend that they contribute significantly to three conceptually distinct problems, which I will refer to as the problem of generalization, the problem of 
flexibility, and the problem of disembodiment. My project is to highlight issues that are already present, but not always identified, in the literature.

\section{Conceptual grounding}

Concepts aggregate information about category exemplars that has become relevant or useful across different situations. Consider the pedestrian concept DOG. Our experiences of dogs often involve various forms of perceptual, motor, affective, social, and linguistic information. We see, touch, smell, pet, love, fear, train, and talk about dogs. Where amodal and embodied/grounded theories diverge is with respect to how this information is represented. According to the former models, it is encoded in amodal symbols contained within a self-contained semantic memory system (J. R. Anderson, 1983). According to the latter, it is grounded in the systems used to experience and interact with dogs. This would likely include visual representations of size, shape, color, and movement; tactile representations of fur; auditory representations of barking and panting, affective representations associated with interacting with dogs, and so on (Barsalou, 1999, 2008; Lynott \& Connell, 2010; Prinz, 2002). Conceptual representations, by these lights, are distributed and multimodal. For the most part, embodied theories also hold that concepts are tokened in a context-dependent fashion, with only a subset of the available modal representations being retrieved on any given occasion.

Although extensive reviews are available elsewhere (e.g., Fischer \& Zwaan, 2008; Kemmerer, 2010; Kiefer \& Pulvermüller, 2012), it is worth surveying some of the evidence in favor of modality-specific representations now, because I am going to survey some of the related, but divergent, evidence in favor of amodal representations later. A caveat is warranted, though. I am not going to offer a full defense of conceptual grounding. Instead, working with the assumption that this idea is attractive for a number of reasons, I am going to examine the special problems posed by abstract concepts for embodied cognition. It is worth emphasizing, though, that these problems extend beyond embodied cognition. Indeed, they apply to any approach that appeals to a notion of neural reuse or "borrowed cognition" (Anderson, 2014).

Returning to the evidence for grounded cognition, a number of neuroimaging studies have seemed to implicate sensorimotor areas in conceptual processing. For example, the recognition of words highly associated with auditory features (e.g., telephone) elicited activity in areas of the auditory association cortex that are active during sound perception (Kiefer, Sim, Herrnberger, Grothe, \& Hoenig, 2008). This activity was not found with words highly associated with visual or motor features. Event-related potentials (ERPs) recorded with the same stimuli suggest that this increased activity begins around
$150 \mathrm{~ms}$ after word onset (Kiefer et al., 2008). Taken together, the fMRI and ERP data suggest that the response is both rapid and selective. Supporters of embodiment argue that such rapidity and selectivity suggest that this activity is causally relevant to the semantic task, but others have pointed out that noncausal explanations are possible. For example, this activity could be the consequence of spreading activation initiated by amodal conceptual processing (Mahon, 2015; Mahon \& Caramazza, 2008).

A number of studies have shown similar indications of correlated activity in perceptual and conceptual tasks. Reading action-related words and sentences produces increased activation in the cortical regions associated with performing the relevant movements (Hauk, Johnsrude, \& Pulvermüller, 2004; Tettamanti et al., 2005). Right- and left-handers have been shown to exhibit increased activation in the premotor areas that were contralateral to their dominant hands when carrying out a lexical decision task on manual-action verbs (Willems, Hagoort, \& Casasanto, 2010). Reading odorrelated words (e.g., cinnamon) appears to elicit increased activity in olfactory regions, when compared to neutral words (Gonzalez et al., 2006). Simmons et al. (2007) provided evidence of a shared neural substrate associated with the perception of color and a property verification task involving color (e.g., taxi-yellow). Because this substrate involves an anterior region of the left fusiform gyrus rather than a posterior region (which is associated with low-level color perception), there is some dispute concerning the degree to which it supports conceptual grounding. Critics of grounding (e.g., Chatterjee, 2010; Mahon, 2015; Mahon \& Caramazza, 2008) argue that what the researchers actually found is shared activation in an amodal area associated with conceptual processing that is near to, but independent of, color perception areas. Simmons and colleagues acknowledged this possibility, but argued that other evidence shows that the more anterior region plays a role in higher-level color perception.

Behavioral studies have provided further indication that our concepts are grounded in the perception, action, and emotion systems. To give just a few examples, Pecher, Zeelenberg, and Barsalou (2003; see also van Dantzig, Pecher, Zeelenberg, \& Barsalou, 2008) demonstrated a modality-switching cost associated with a property verification task: Participants verified verbally expressed facts involving one modality (leaves rustle) more rapidly after verifying a fact involving the same modality (blenders make noise) than after verifying a fact involving a different modality (cranberries are tart). Glenberg and Kaschak (2002) found a decrease in reaction times when the response direction (a button pressed either away/toward the body) and the implied direction of action of the sentences (e.g., Andy gave you the pizzal You gave Andy the pizza) were congruent. Borghi, Glenberg, and Kaschak (2004) uncovered a similar action-compatibility effect when participants were instructed to decide whether or 
not a word that followed a sentence named a part of the object mentioned in the sentence. Half of the selected parts were found in the upper portion of the object, and half were found in the lower portion. The experimenters observed that responses were faster when the direction of the keypress movement (upward or downward) matched the part location. Kaschak and colleagues (2005) found that watching upward or downward motion slowed the semantic processing of sentences describing motion in the same direction (see also Meteyard, Bahrami, \& Vigliocco, 2007). There is an active discussion among researchers concerning why congruency can lead to facilitation in some tasks and interference in others (Willems \& Francken, 2012).

The evidence from neuropsychology is equivocal (Mahon, 2015; McCaffrey, 2015). On the one hand, damage to the auditory association cortex has been linked to impairment of the processing of sound-related concepts (Trumpp, Kliese, Hoenig, Haarmeier, \& Kiefer, 2013). Similarly, a selective deficit in action-concept processing has also been found in patients with apraxia (Buxbaum \& Saffran 2002), motor neuron disease (Bak, O'Donovan, Xuereb, Boniface, \& Hodges, 2001) and Parkinson's (Boulenger et al., 2008; Fernandino et al., 2012; Fernandino et al., 2013). On the other hand, it seems much more common to find preserved conceptual processing in the face of damage to action-related sensorimotor areas (Johnson-Frey, 2004; Mahon \& Caramazza, 2005). Binder and Desai (2011, p. 531) drew the following conclusion from their review of the extant evidence: "conceptual deficits in patients with sensory-motor impairments, when present, tend to be subtle rather than catastrophic." As I will discuss in subsequent sections, the multifaceted nature of the neuropsychological evidence is a driving force behind recent attempts to adopt hybrid modal/amodal approaches to semantic memory.

Some transcranial magnetic stimulation (TMS) research supports grounding. For instance, Pulvermüller, Hauk, Nikulin, and Ilmoniemi (2005) carried out an rTMS study in which they weakly stimulated different parts of the motor system while participants performed a lexical decision task on arm- and leg-related action words. Response times increased with arm-related words when there was weak stimulation of left hemisphere areas associated with arm movement, and response times increased with leg-related words when there was weak stimulation of motor areas associated with leg movement, but response times were not modulated in a control condition with sham stimulation.

We should remain circumspect with respect to this body of evidence, for a number of reasons. Viewed charitably, it implicates modality-specific representations in our concepts. Even from this charitable perspective, though, several caveats are warranted. First, this evidence falls well short of showing that modality-specific representations are necessary for conceptual processing. Second, it does not exclude amodal representations - particularly when one considers the possibility that some of the results might involve amodal areas that are near to perception or action areas (Chatterjee, 2010; Mahon, 2015; Mahon \& Caramazza, 2008; Weiskopf, 2007). Finally, because the relevant studies overwhelmingly rely on concrete or highly imageable concepts, the status of abstract concepts remains very much in question (Chatterjee, 2010; Dove, 2009, 2011; Mahon \& Caramazza, 2008).

\section{Problem 1: Generalization}

The main thesis of this essay is that abstract concepts pose three distinct problems for embodied and grounded cognition. The first I will refer to as the problem of generalization. Within cognitive psychology, conceptual generalization can be understood in both a horizontal and a vertical sense. The horizontal sense concerns the extension of concepts to include new exemplars, whereas the vertical sense concerns the creation of conceptual hierarchies in which superordinate concepts are more general than subordinate ones (Rosch, 1978). For example, we can situate a basic-level concept like DOG within a hierarchy in which PUG is more specific and MAMMAL is more general. Although distinct, these two senses of generalization are clearly related to each other, because both concern how we are able to represent information about the world that goes beyond our immediate experience. The first sense of generalization treats this as universal problem for concepts, and the second highlights the fact that the problem may be more acute for some concepts than others.

It is not uncommon to define abstract concepts in terms of generalization understood in a vertical sense. Researchers in epigenetic robotics, for instance, explicitly characterize them as "higher-order" concepts (Cangelosi \& Riga, 2006; Stramandinoli, Marocco, \& Cangelosi, 2012; Thill, Pado, \& Ziemke, 2014). Others disagree. Borghi and Binkofski (2014), for instance, suggested that we need to distinguish abstractness from mere abstraction. Some examples may help to elucidate this distinction. A concept such as MAMMAL may sit at the top of an abstraction hierarchy, and is thus more abstract than related lower-order concepts, but its referents are nevertheless concrete, perceivable objects. A concept like ODD NUMBER, on the other hand, is abstract because its referents are not concrete, perceivable objects but, instead, something more ephemeral. Borghi and Binkofski contended that abstractness, not abstraction, is the real problem posed by abstract concepts. This essay takes a different stance, and views abstraction and abstractness as related but distinct problems posed by abstract concepts. The former is associated with the problem of generalization, and the latter is associated with the problem of disembodiment.

Some researchers contend that fully grounded theories are not up to the task of addressing the problem of generalization. 
Patterson, Nestor, and Rogers (2007, p. 977), for instance, wrote: "If semantic memory consisted only of the modalityspecific content of objects (and the links between them), it is doubtful that we could ever achieve the higher-order generalizations on which so much of our semantic processing relies." Conceptually, amodal representations provide an effective means of integrating information from multiple sources (Dove, 2009; Machery, 2007). In keeping with this, a controversy has arisen concerning whether or not theories of embodied cognition should make room for them. Meteyard, Cuadrado, Bahrami, and Vigliocco (2012) suggested that we can place different variants of embodied cognition along a continuum ranging from the strongly to the weakly embodied: At the strongly embodied end are theories that fully limit cognition to action, emotion, and perception systems (e.g., Gallese \& Lakoff, 2005; Glenberg \& Gallese, 2012; Pulvermüller, 2001); at the weakly embodied end are theories that see the activation of sensorimotor areas as a secondary consequence of cognitive processing handled by amodal areas (e.g., Chatterjee, 2010; Mahon, 2015; Mahon \& Caramazza, 2008); and in between are theories that advocate for some sort of intermediate position at which concepts are at least partially grounded in action and perception systems (e.g., Binder \& Desai, 2011; Simmons \& Barsalou, 2003; Vigliocco, Vinson, Lewis, \& Garrett, 2004).

Two bodies of evidence seem to implicate amodal representations in semantic memory. The first involves neuropsychological patients with disorders such as semantic dementia (SD). SD is characterized by a gradual bilateral atrophy of the temporal lobes and a concomitant progressive loss of semantic memory for common objects (Hodges, Bozeat, Lambon Ralph, Patterson, \& Spatt, 2000; Lambon Ralph, McClelland, Patterson, Galton, \& Hodges, 2001; Lambon Ralph, Sage, Jones, \& Mayberry, 2010; Patterson, Graham, \& Hodges, 1994). SD patients often exhibit degraded knowledge of several items within a larger category, but have preserved knowledge for others. For example, a patient who was assessed longitudinally initially had trouble in a picture-naming task with the concepts EAGLE and OSTRICH, but not with CHICKEN, DUCK, and SWAN (Hodges, Graham, \& Patterson, 1995; Patterson et al., 2007). The deficit associated with these items is typically cross-modal (Bozeat, Lambon Ralph, Patterson, Garrard, \& Hodges, 2000; Garrard \& Carroll, 2006; McCaffrey \& Machery, 2012). Remarkably, the degradation of semantic knowledge in SD often proceeds in a hierarchical fashion. For example, as the patient mentioned above gradually lost the ability to identify more and more bird species, she remained able to identify most of them as birds or animals (Hodges et al., 1995; Patterson et al., 2007).

The second body of evidence involves neurotypical participants. Some research in cognitive neuroscience suggests that amodal representations might be important to semantic memory. To give an example, stimulating anterior temporal areas with TMS leads to decreased efficiency with respect to semantic-processing tasks (Pobric, Jefferies, \& Lambon Ralph, 2010). Although this decreased performance falls well short of the catastrophic semantic impairments found in SD patients, it does implicate the anterior temporal lobes in semantic processing. Other studies have implicated other potentially amodal areas. Binder, Desai, Graves, and Conant (2009), for example, carried out a meta-analysis of 120 neuroimaging studies that contrasted semantic and nonsemantic control tasks and found that several heteromodal areas in left temporal and parietal cortex were regularly engaged by these tasks. In sum, a plethora of non-modality-specific areas have been implicated in semantic processing.

Evidence of the sort outlined above is often seen as either a vindication of a traditional amodal approach or as demonstration of the need for a hybrid approach. Recently, a particular class of intermediate theories has become popular. These expand on the notion of convergence zones (Damasio \& Damasio, 1994) and posit amodal "hubs" that radiate to modality-specific "spokes" in sensorimotor areas (Lambon Ralph, Pobric, \& Jefferies, 2009; Patterson et al., 2007). One of the more influential of these hub-and-spoke theories locates a core, amodal hub for conceptual processing bilaterally in the anterior temporal lobes (Jefferies \& Lambon Ralph, 2006; Lambon Ralph et al., 2010; Pobric et al., 2010). Related theories have identified several hubs and offer a more dynamic view of the interaction between amodal and modality-specific systems (Binder \& Desai, 2011; Reilly et al., 2014; Reilly \& Peelle, 2008; Reilly, Rodriguez, Peelle, \& Grossman, 2011; Watson \& Chatterjee, 2011).

This essay is not the place to settle the ongoing debate between stronger and weaker approaches to embodied cognition. Certainly, many think that abstract concepts can be handled without amodal representations (e.g., Gallese \& Lakoff, 2005; Vigliocco et al., 2014; Wilson-Mendenhall, Simmons, Martin, \& Barsalou, 2013). What seems clear, though, is that the issue of generalization has become a battleground in this debate. One of the central issues is whether neuropsychological disorders such as SD, which involves cross-modal deficits and progresses in hierarchical fashion, suggest that amodal hubs play a significant role in semantic memory (McCaffrey, 2015; McCaffrey \& Machery, 2012; Patterson et al., 2007; Reilly et al., 2014).

\section{Problem 2: Flexibility}

From a grounded perspective - in which physical environments, situations, states of the body, and current tasks are all influences on our how concepts are realized - concepts are often treated as being inherently flexible. Barsalou (1999, 2008, 2012), to give an example, consistently emphasizes the situated nature of concepts. Lebois, Wilson-Mendenhall, 
and Barsalou (2014) contended that the activation of grounded features of concepts varies dynamically with context. Connell and Lynott (2014) contended that the dynamic influences that the body, the environment, the relevant goals, and the task have on our conceptual representations imply that "you can't represent the same concept twice." A. D. Wilson and Golonka (2013) maintained that task-dependence is a key feature of embodied cognition. The problem of flexibility arises because there is good reason to think that embodied representations can be engaged to a greater or lesser degree depending on a number of factors, including not only the context, current goals, and task, but also the relative abstractness of the concepts involved.

For some time, there has been some indication that embodied representations may not be necessary for all conceptual processing. For example, patients with SD and Alzheimer's disease can show action-word deficits despite the relative preservation of frontal areas associated with motor planning (Druks et al., 2006; Reilly, Cross, Troiani, \& Grossman, 2007; Yi, Moore, \& Grossman, 2007). Research now indicates that context may determine whether or not sensorimotor systems are engaged with individual concepts. In other words, it appears that some individual concepts can be used in either a more or a less grounded fashion, depending on the circumstances.

Metaphoric language is a useful testing ground for this idea, because it uses words that typically express concrete contents to express more abstract contents. Some of the relevant research has focused on motor and visual areas that appear to be engaged during certain conceptual tasks. For example, a number of studies have shown that effector-specific motor and premotor areas are engaged by action words associated with particular body parts (for reviews, see Kemmerer, 2010; Kiefer \& Pulvermüller, 2012; Willems \& Casasanto, 2011). Similarly, studies have also indicated that areas associated with visual motion can be engaged by action words or action sentences (Kable, Kan, Wilson, Thompson-Schill, \& Chatterjee, 2005; Kable, Lease-Spellmeyer, \& Chatterjee, 2002; Saygin, McCullough, Alac, \& Emmorey, 2010). Some research has indicated that the effector-specific activations associated with the semantic processing of action words does not appear if the words are used in metaphors (Aziz-Zadeh, Wilson, Rizzolatti, \& Iacoboni, 2006) or idioms (Raposo, Moss, Stamatakis, \& Tyler, 2009). Building on the finding that sentences describing upward or downward motion can interfere with the shape perception of a visual object presented in the relevant region (Richardson, Spivey, Barsalou, \& McCrae, 2003), Bergen, Lindsay, Matlock, and Narayanan (2007) carried out a number of experiments with three different types of sentences. They found interference effects with literal motion sentences, but not with metaphorical motion sentences or abstract sentences. Saygin, McCullough, Alac, and Emmorey (2010) carried out an fMRI experiment in which they compared motion sentences (The wild horse crossed the barren field), fictive motion sentences (The hiking trail crossed the barren field), and static sentences. Motionsensitive visual areas were activated significantly more with the motion sentences than the other two sentence types, but they were also more active with the fictive sentences than they were with the static ones. In a similar vein, Desai, Conant, Binder, Park, and Seidenberg (2013) compared the neural responses to three analogous types of sentences: those expressing "literal" action (the daughter grasped the flowers), those expressing "metaphoric" action (the public grasped the idea), and those expressing "abstract" action (the public understood the idea). Two of their findings are relevant to our present concerns. First, in the "literal" and "metaphoric" conditions, they found that the degree of activity in primary motor and visual motion areas was inversely correlated with the familiarity ratings of the sentences. Second, in the "metaphor" and "abstract" conditions, they found increased activation in left temporal regions. They suggested that these findings fit with both the proposal that metaphors undergo a gradual abstraction process as they gain familiarity (Bowdle \& Gentner, 2005) and the proposal that our understanding of metaphors depends in part on amodal systems.

It should be noted that a supporter of an amodal approach might take the findings of decreased activation with fictive and metaphoric contexts as supporting their claim that sensorimotor activation during conceptual tasks is epiphenomenal. The possible need for a more nuanced solution to the problem of flexibility is suggested by a recent study comparing patients with Parkinson's disease to age-matched controls, which showed a selective impairment for the semantic processing of literal action sentences and idiomatic action sentences, but no impairment for the semantic processing of nonidiomatic metaphoric action sentences and abstract sentences (Fernandino et al., 2013).

This research on metaphor highlights how the problem of flexibility might apply to a particular domain, but it is not the only research area where this pattern emerges. For instance, sentences from second-person perspectives (You gave a pizza to Louis) but not sentences from third-person perspectives (Lea gave a pizza to Louis) generated an actioncompatibility effect (Gianelli, Farnè, Salemme, Jeannerod, \& Roy, 2011). Similarly, motor-evoked potentials have been found to increase for first-person but not for third-person action verbs (Papeo, Corradi-Dell'Acqua, \& Rumiati, 2011). Coming at the issue of flexibility from a different angle, there is evidence that larger narratives can selectively engage grounded representations (Chow et al., 2014; Kurby \& Zacks, 2013).

As was true with the problem of generalization, the problem of flexibility figures prominently in some recent theoretical reassessments of embodied cognition. After highlighting the variability of the extant evidence, Willems and Francken 
(2012) suggested that we need to go beyond the embodied/ disembodied dichotomy and develop explicit theories concerning the relative contributions of embodied representations. Others have contended that we need to reevaluate embodied cognition and recognize that different conceptual tasks may involve different degrees of embodiment (Pulvermuller \& Garagnani, 2014; Watson \& Chatterjee, 2011; Zwaan, 2014). Wellsby and Pexman (2014) suggested that sensorimotor representations may even play different roles at different stages of development.

\section{Problem 3: Disembodiment}

The third problem posed by abstract concepts emerges because they appear to be qualitatively different from other concepts. It is just difficult to see how representations grounded in sensorimotor systems can, even in principle, capture the content of abstract concepts such as ODD NUMBER, JUSTICE, and TRUTH. No matter how these concepts are realized in the brain, these categories are in some important sense divorced from experiential factors. They appear to be disembodied. Even those who claim that abstract concepts are fully grounded acknowledge that such examples present a special challenge. For instance, Wilson-Mendenhall, Simmons, Martin, and Barsalou (2013, p. 921) explained, "theories of grounded cognition suggest that individual abstract concepts are represented by distributed neural patterns that reflect their unique content, which is often more situationally complex and temporally extended than that of concrete concepts." Borghi and Binkofski (2014) offered a broad operational definition of abstract concepts. According to this definition, abstract concepts tend to refer to events, mental states, and situations rather than concrete, manipulable objects or entities; to involve more complex properties and relations than concrete concepts; and to be semantically more variable. The difficulty in capturing concepts with this cluster of features is what I am calling the problem of disembodiment.

A longstanding and diverse body of evidence suggests that abstract concepts are processed in a functionally and neuroanatomically different way than other concepts (with the caveat that the difference may be a matter of a degree rather than a straightforward dichotomy). Concreteness or imageability effects were an early indication of this difference. Concreteness is typically defined as the extent to which an item or event can be experienced by the senses, and imageability is typically defined in terms of the subjective ease with which a word gives rise to sensorimotor mental imagery. Because these two measures overlap to a great degree, researchers have tended to treat them as interchangeable (although see Vigliocco, Vinson, Druks, Barber, \& Cappa, 2011, for a discussion of their differences). In general, concrete/high-imageable words exhibit a number of processing advantages over abstract/low-imageable words (Paivio, 1986; Wattennmaker \& Shoben, 1987). More recently, a motor-related measure has been used to similar effect. The dimension of body-object interaction (BOI) is meant to capture the ease with which a human body can physically interact with category exemplars. A number of studies have indicated that words with higher BOI ratings are processed more efficiently than words with lower BOI ratings (Siakaluk et al., 2008; Wellsby, Siakaluk, Owen, \& Pexman, 2011; Yap, Pexman, Wellsby, Hargreaves, \& Huff, 2012).

Evidence from cognitive neuroscience broadly supports a neurophysiological distinction between abstract/lowimageable and concrete/high-imageable concepts. For instance, Adorni and Proverbio (2012) applied LORETA source reconstruction to an ERP experiment involving a lexical decision task and found evidence of increased activation of the left medial frontal gyrus and the left temporal cortex, as well as decreased activation of extrastriate visual areas, with abstract relative to concrete words (see Lehmann, Pascual-Marqui, Strik, \& Koenig, 2010, for similar findings using different tasks). In another ERP study, distinct concreteness effects were elicited in the left and right hemispheres (Huang, Lee, $\&$ Federmeier, 2010). A number of neuroimaging studies have shown that superior regions of the left temporal lobe (Binder, Westbury, McKiernan, Possing, \& Medler, 2005; Giesbrecht, Gamblin, \& Swaab, 2004; Mellet, Tzourio, Denis, \& Mazoyer, 1998; Noppeney \& Price, 2004; Sabsevitz, Medler, Seidenberg, \& Binder, 2005) and inferior regions of the left prefrontal cortex (Binder et al., 2005; Giesbrecht et al., 2004; Goldberg, Perfetti, \& Schneider, 2006; Noppeney \& Price, 2004; Sabsevitz et al., 2005) are activated to a greater degree by tasks involving abstract concepts. Although there is some variability in the imaging data taken as whole, recent meta-analyses have shown that these areas are the most likely to show increased activation with abstract concepts (Binder, Desai, Graves, \& Conant, 2009; Wang, Conder, Blitzer, \& Shinkareva, 2010). In a recent study, Sakreida et al. (2013) presented simple sentences that contained pairs of abstract, concrete, or mixed (abstract-concrete and concrete-abstract) words and found that the fully abstract pairs engaged the left middle temporal gyrus, whereas the fully concrete pairs engaged a fronto-parietal network.

Neuropsychological research provides further reason to suppose that abstract/low-imageable and concrete/highimageable concepts are partially supported by distinct neurological systems. A greater impairment for the processing of abstract words has been correlated with left hemisphere damage, including patients who present with aphasia (Goodglass, Hyde, \& Blumsten, 1969), deep dyslexia (Coltheart, Patterson, \& Marshall, 1980; Franklin, Howard, \& Patterson, 1995; Shallice \& Warrington, 1975), and deep dysphasia (Katz \& Goodglass, 1990; Martin \& Saffran, 1992). Interestingly, some patients with SD can exhibit a contrasting 
impairment for concrete/high-imageable words (Reilly \& Peelle, 2008; Yi et al., 2007). There is an active discussion among researchers concerning whether (e.g., Bonner et al., 2009) or not (e.g., Hoffman \& Lambon Ralph, 2011) this reversal is a typical feature of SD. A recent study of healthy participants also supports an abstract/concrete asymmetry. Papagno, Fogliata, Catricala, and Miniussi (2009) found that accuracy on a lexical decision task decreased with abstract concepts when rTMS was applied over the left inferior frontal gyrus and the left superior temporal gyrus, but accuracy decreased with concrete concepts when rTMS was applied over the right superior temporal gyrus.

Ultimately, there is ongoing debate concerning how to handle the problem of disembodiment. Some maintain that a fully embodied solution is possible, while others maintain that an alternative solution is needed. There is general agreement, however, that fully abstract concepts represent a special challenge for embodied cognition.

\section{Do multiple problems require multiple solutions?}

Thus far I have argued that abstract concepts pose at least three distinct problems for grounded cognition: the problems of generalization, flexibility, and disembodiment. Although this trifurcation does not in and of itself mean that a single theory cannot address all three problems, it does raise the possibility that more than one theory may be required. Once we move beyond a pretheoretical notion of abstractness and look at the specific issues engendered by the diverse bodies of research on abstract concepts, we are in a better position to assess and develop our theories. To see this, consider some of the recent theoretical proposals and their potentials with respect to solving the problems outlined in this essay:

Conceptual metaphor Cognitive linguists (e.g., Lakoff, 1987; Lakoff \& Johnson, 1980) have proposed that we often understand abstract concepts metaphorically in terms of experiential concepts. This is supported by some behavioral research from an embodied and grounded perspective (reviewed by Gibbs, 2006). For instance, Boroditsky and colleagues (Boroditsky \& Ramscar, 2002; Casasanto \& Boroditsky, 2008) provided evidence that some temporal judgments rely on spatial representations. However, there is reason to suspect that the explanatory scope of this approach is likely to be limited. First, conceptual metaphors do not seem well suited to addressing the problem of generalization, because this problem arises in nonmetaphoric contexts. Second, some of the evidence reviewed above suggests that it is not the case that all metaphoric language engages action and perception systems. Conceptual metaphors are thus unlikely even to be able to explain all metaphoric language. Third, although conceptual metaphors have some promise with respect to the problem of disembodiment, it is far from clear that all abstract concepts can be accounted for in terms of conceptual metaphors.

Embodied dual-code theories Recently, several embodied versions of dual-code theory (Paivio, 1986) have been offered. According to the language-and-situated-simulation (LASS) theory (Barsalou, Santos, Simmons, \& Wilson, 2008), language comprehension involves the continuous interaction between the processing of linguistic forms and situated simulations. Another example is the word-as-tool (WAT) theory (Borghi \& Binkofski, 2014; Borghi \& Cimatti, 2009). In WAT, linguistic forms are not merely a means of engaging simulations but, instead, a means of leveraging our social experience. Abstract concepts require longer-lasting social interaction than concrete concepts to be acquired, and this leads to their greater reliance on linguistic simulations (Borghi \& Binkofski, 2014; Scorolli et al., 2011). These theories share the idea that internalized language serves as an additional conceptual format (see also Cangelosi \& Riga, 2006; Paivio, 2013; Vygotsky, 2012). The symbolic properties of language could help explain how we are able to handle disembodied content (Clark, 2008; Dove, 2014). Language-based cognition could also provide partial solution to the problem of flexibility by explaining how conventional or "dead" metaphors work without the engagement the sensorimotor representations associated with their "literal" reading. The ability to affix arbitrary labels to categories is also likely to help us acquire higher-order concepts (Cangelosi \& Riga, 2006; Carey \& Sarnecka, 2006; Dehaene, Spelke, Pinel, Stanescu, \& Tviskin, 1999). However, given that generalization seems possible in the absence of labels, this approach may not offer a full solution to the problem of generalization.

Embodied/distributional hybrids There have been a number of recent attempts to merge embodied and distributional approaches to semantic memory (Andrews, Frank, \& Vigliocco, 2014; Andrews, Vigliocco, \& Vinson, 2009; Louwerse, 2011; Lourwerse \& Jeuniaux, 2008; Riordan \& Jones, 2010; Vigliocco, Meteyard, Andrews, \& Kousta, 2009; Vigliocco, Vinson, Lewis, \& Garrett, 2004). Perhaps the greatest impetus for such accounts is the promise they have with respect to the problem of disembodiment. Distributional models that rely on language-based information seem to be particularly adept at handling abstract content (Louwerse, 2011; Louwerse \& Jeuniaux, 2008), but they struggle to address the grounding problem (Harnad, 1990). For this reason, a hybrid approach seems particularly promising. Some recent evidence supports this impression. To give an example, Andrews, Vigliocco, and Vinson (2009) found that the performance of a model that combined experiential and languagebased distributional data correlated with the behavioral data from several tasks better than the performance of models that used only one type. Although this model only involves 
distinct types of information (and is thus compatible with a purely amodal approach; see Machery, 2007), it fits well with theories that posit distinct types of conceptual representations. Less work has connected this sort of approach to the problems of flexibility and generalization, but such a connection does have some initial plausibility. For one thing, this approach provides a framework for explaining flexibility, because certain tasks and contexts could rely on one type of representation more than the other. For another, mixed embodied/ distributional concepts could explain how abstraction that falls short of abstractness is possible.

Emotions Controlling for age of acquisition, context availability, familiarity, imageability, and other variables, Kousta, Vigliocco, Vinson, Andrews, and Del Campo (2011) found that abstract words have a reaction time advantage over concrete words (reversing the usual concreteness effect). Building on an earlier finding that emotional valence facilitated lexical processing (Kousta, Vinson, \& Vigliocco, 2009; see also Newcombe, Campbell, Siakaluk, \& Pexman, 2012), they theorized that this advantage might be due to the overall tendency for abstract concepts to have greater emotional content (for neuroimaging evidence that fits with these claims, see Vigliocco et al., 2014). These intriguing results may pave the way for a more fully embodied response to the problem of disembodiment. Indeed they appear to show that concepts that we had previously viewed as disembodied are in fact grounded to some degree. What they do not show, however, is that all abstract concepts can be handled in this way (Dove, 2014; Shallice \& Cooper, 2013). Furthermore, while increasing the prominence of emotional content in abstract concepts may provide a partial solution to the problem of disembodiment, it is difficult to see how it would provide a meaningful solution to the problems of generalization and flexibility. For instance, it is not likely to explain how we are able to possess higher-order concepts such as MAMMAL. It is also not likely to explain why sensorimotor systems appear to be robustly engaged in some conceptual contexts but not in others.

Hub-and-spoke theories As was outlined above, working from neuroimaging and neuropsychological case studies, a number of researchers have speculated that concepts rely on both modality-specific systems and amodal hubs. Although this newly dominant approach remains somewhat underspecified and hampered by disagreements concerning the number and location of such hubs, it has some promise with respect to each of the three problems. We have already seen that it has largely been developed in the context of the problem of generalization, but there are reasons to think that it could be extended to the other problems. Perhaps flexibility is the result of the differential engagement of the "spokes" by task and context. Analogously, disembodiment might be explained in terms of the relative influences of "hubs." More research is clearly needed, and the question of how this approach might (or might not) mesh with other hybrid approaches remains.

Multidimensional theories A number of studies have indicated that words with more associated semantic information are processed more efficiently in word recognition tasks than words with less associated semantic information (for a review, see Pexman, 2012). Such semantic-richness effects have been found in relation to several dimensions (e.g., Buchanan, Westbury, \& Burgess, 2001; Duñabeitia, Avilés, \& Carreiras, 2008; Grondin, Lupker, \& McRae, 2009; Schwanenflugel \& Shoben, 1983), and this has led some researchers to offer multidimensional accounts of conceptual structure (e.g., Pexman, Hargreaves, Siakaluk, Bodner, \& Pope, 2008; Yap et al., 2012). Recently, this approach has been extended to abstract concepts. For instance, Zdrazilova and Pexman (2013) examined the effects of six semantic-richness variables (context availability, sensory experience rating, emotional valence, emotional arousal, semantic neighborhood, and number of associates) on a lexical-decision task and a semanticcategorization task. They found that the effects varied with the task: Context availability facilitated lexical decision, and both sensory experience and positive valence facilitated semantic categorization. From this result, Zdrazilova and Pexman (2013, p. 1316) concluded that abstract meaning may be in part grounded in "situations, emotions, and sensory experience." In another study, Moffat, Siakaluk, Sidhu, and Pexman (2015) compared the effects of emotional experience and context availability on a semantic-categorization task. Emotional experience facilitated the processing of abstract words but inhibited the processing of concrete words, whereas context availability facilitated both. One of the important features of the semantic-richness research is that the effects associated with different dimensions are often task-dependent (Hargreaves \& Pexman, 2012; Moffat et al., 2015; Siakaluk, Knol, \& Pexman, 2014; Zdrazilova \& Pexman, 2013).

Troche, Crutch, and Reilly (2014) have offered a different defense of a multidimensional approach to abstract concepts. Rather than rely on an intuitive notion of abstractness, they investigated how the meanings of 400 concrete and abstract English nouns are distributed in a multidimensional space using hierarchical cluster analysis. Participants rated the nouns along 12 dimensions. Factor reduction yielded three latent factors that the authors characterize as affective association, perceptual salience, and magnitude. When the original words were plotted for these three factors, abstract and concrete words were associated with unique, but somewhat overlapping, topographies within this space.

Although much more work needs to be done from within multidimensional frameworks, these examples demonstrate 
the promise that such frameworks have for helping us evaluate and possibly integrate the theories outlined above as we address the problems of generalization, flexibility, and disembodiment.

\section{Conclusion}

Traditionally, cognitive science has examined our concepts from a computational perspective that views cognition as being functionally independent from perception and action (Hurley, 2008). Embodied cognition offers an alternative framework, one that views cognition as being fundamentally grounded in sensory and motor systems. In this heterogeneous and constantly evolving research program (Barsalou, 2008; Gibbs, 2006; Wilson, 2002), abstract concepts have been seen as an important challenge. In this essay, I have argued that abstract concepts pose three separate problems for embodied cognition: the problem of generalization, the problem of flexibility, and the problem of disembodiment. Recognizing that these problems should not be conflated will hopefully facilitate the development of more robust embodied theories of concepts.

\section{References}

Adorni, R., \& Proverbio, A. M. (2012). The neural manifestation of the word concreteness effect: An electrical neuroimaging study. Neuropsychologia, 50, 880-891.

Anderson, J. R. (1983). The architecture of cognition. Hillsdale, NJ: Erlbaum.

Anderson, M. L. (2014). After phrenology: Neural reuse and the interactive brain. Cambridge, MA: MIT Press.

Andrews, M., Frank, S., \& Vigliocco, G. (2014). Reconciling embodied and distributional accounts of meaning in language. Topics in Cognitive Science, 6, 359-370.

Andrews, M., Vigliocco, G., \& Vinson, D. (2009). Integrating experiential and distributional data to learn semantic representations. Psychological Review, 116, 463-498. doi:10.1037/a0016261

Aziz-Zadeh, L., Wilson, S. M., Rizzolatti, G., \& Iacoboni, M. (2006). Congruent embodied representations for visually presented actions and linguistic phrases describing actions. Current Biology, 16, 1818-1823.

Bak, T. H., O’Donovan, D. G., Xuereb, J. H., Boniface, S., \& Hodges, J. R. (2001). Selective impairment of verb processing associated with pathological changes in Brodmann areas 44 and 45 in the motor neurone disease-dementia-aphasia syndrome. Brain, 124, 103-120.

Barsalou, L. W. (1999). Perceptual symbol systems. Behavioral and Brain Sciences, 22, 577-609. doi:10.1017/S0140525X99002149. disc. 609-660.

Barsalou, L. W. (2008). Grounded cognition. Annual Review of Psychology, 59, 617-645. doi:10.1146/annurev.psych.59.103006. 093639

Barsalou, L. W. (2010). Grounded cognition: Past, present, and future. Topics in Cognitive Science, 2, 716-724. doi:10.1111/j.1756-8765. 2010.01115.x
Barsalou, L. W. (2012). The human conceptual system. In M. Spivey, K. McRae, \& M. Joanisse (Eds.), The Cambridge handbook of psycholinguistics (pp. 239-258). New York, NY: Cambridge University Press.

Barsalou, L. W., Santos, A., Simmons, W. K., \& Wilson, C. D. (2008). Language and simulation in conceptual processing. In M. De Vega, A. M. Glenberg, \& A. C. Graesser (Eds.), Symbols and embodiment: Debates on meaning and cognition (pp. 245-284). New York, NY: Oxford University Press.

Barsalou, L. W., \& Wiemer-Hastings, K. (2005). Situating abstract concepts. In D. Pecher \& R. Zwaan (Eds.), Grounding cognition: The role of perception and action in memory, language, and thought (pp. 129-163). Cambridge, UK: Cambridge University Press.

Bergen, B., Lindsay, S., Matlock, T., \& Narayanan, S. (2007). Spatial and linguistic aspects of visual imagery in sentence comprehension. Cognitive Science, 31, 733-764.

Binder, J. R., \& Desai, R. H. (2011). The neurobiology of semantic memory. Trends in Cognitive Sciences, 15, 527-536.

Binder, J. R., Desai, R. H., Graves, W. W., \& Conant, L. L. (2009). Where is the semantic system? A critical review and meta-analysis of 120 functional neuroimaging studies. Cerebral Cortex, 19, 2767-2796. doi:10.1093/cercor/bhp055

Binder, J. R., Westbury, C., McKiernan, K., Possing, E., \& Medler, D. (2005). Distinct brain systems for processing concrete and abstract concepts. Journal of Cognitive Neuroscience, 17, 905-917.

Bonner, M. F., Vesely, L., Price, C., Anderson, C., Richmond, L., Farag, C.,...Grossman, M. (2009). Reversal of the concreteness effect in semantic dementia. Cognitive Neuropsychology, 26, 568-579.

Borghi, A. M., \& Binkofski, F. (2014). Words as social tools: An embodied view on abstract concepts (Briefs in Cognition series). New York, NY: Springer.

Borghi, A. M., \& Cimatti, F. (2009). Words as tools and the problem of abstract words meanings. In N. Taatgen \& H. van Rijn (Eds.), Proceedings of the 31st Annual Conference of the Cognitive Science Society (pp. 2304-2309). Austin, TX: Cognitive Science Society.

Borghi, A. M., Glenberg, A. M., \& Kaschak, M. P. (2004). Putting words in perspective. Memory \& Cognition, 32, 863-873. doi:10.3758/ BF03196865

Boroditsky, L., \& Ramscar, M. (2002). The roles of body and mind in abstract thought. Psychological Science, 13, 185-189. doi:10.1111/ 1467-9280.00434

Boulenger, V., Mechtouff, L., Thobois, S., Broussolle, E., Jeannerod, M., \& Nazir, T. A. (2008). Word processing in Parkinson's disease is impaired for action verbs but not for concrete nouns. Neuropsychologia, 46, 743-756.

Bowdle, B. F., \& Gentner, D. (2005). The career of metaphor. Psychological Review, 112, 193-216. doi:10.1037/0033-295X.112.1.193

Bozeat, S., Lambon Ralph, M. A., Patterson, K., Garrard, P., \& Hodges, J. R. (2000). Non-verbal semantic impairment in semantic dementia. Neuropsychologia, 38, 1207-1215.

Buchanan, L., Westbury, C., \& Burgess, C. (2001). Characterizing semantic space: Neighborhood effects in word recognition. Psychonomic Bulletin \& Review, 8, 531-544.

Buxbaum, L. J., \& Saffran, E. M. (2002). Knowledge of object manipulation and object function: Dissociations in apraxic and nonapraxic subjects. Brain and Language, 82, 179-199.

Cangelosi, A., \& Riga, T. (2006). An embodied model for sensorimotor grounding and grounding transfer: Experiments with epigenetic robots. Cognitive Science, 30, 673-689.

Carey, S., \& Sarnecka, B. W. (2006). The development of human conceptual representations. In M. Johnson \& Y. Munakata (Eds.), Processes of change in brain and cognitive development: Attention and performance XXI (pp. 473-496). New York, NY: Oxford University Press. 
Casasanto, D., \& Boroditsky, L. (2008). Time in mind: Using space to think about time. Cognition, 106, 579-593.

Chatterjee, A. (2010). Disembodying cognition. Language and Cognition, 2, 79-116.

Chow, H. M., Mar, R. A., Xu, Y., Liu, S., Wagage, S., \& Braun, A. R. (2014). Embodied comprehension of stories: Interactions between language regions and modality-specific neural systems. Journal of Cognitive Neuroscience, 26, 279-295.

Clark, A. (2008). Supersizing the mind: Embodiment, action, and cognitive extension. Oxford, UK: Oxford University Press.

Coltheart, M., Patterson, K., \& Marshall, J. C. (Eds.). (1980). Deep dyslexia. London, UK: Routledge \& Kegan Paul.

Connell, L., \& Lynott, D. (2014). Principles of representation: Why you can't represent the same concept twice. Topics in Cognitive Science, 6, 390-406.

Damasio, A. R., \& Damasio, H. (1994). Cortical systems for retrieval of concrete knowledge: The convergence zone framework. In C. Koch \& J. L. Davis (Eds.), Large-scale neuronal theories of the brain: Computational neuroscience (pp. 61-74). Cambridge, MA: MIT Press.

Dehaene, S., Spelke, E., Pinel, P., Stanescu, R., \& Tviskin, S. (1999). Sources of mathematical thinking: Behavioral and brain imaging evidence. Science, 284, 970-974.

Desai, R. H., Conant, L. L., Binder, J. R., Park, H., \& Seidenberg, M. (2013). A piece of the action: Modulation of sensory-motor regions by idioms and metaphors. NeuroImage, $83,862-869$.

Dove, G. (2009). Beyond perceptual symbols: A call for representational pluralism. Cognition, 110, 412-431.

Dove, G. (2011). On the need for embodied and dis-embodied cognition. Frontiers in Cognition, 1(242), 1-13.

Dove, G. (2014). Thinking in words: Language as an embodied medium of thought. Topics in Cognitive Science, 6, 371-389.

Druks, J., Masterson, J., Kopelman, M., Clare, L., Rose, A., \& Rai, G. (2006). Is action naming better preserved (than object naming) in Alzheimer's disease and why should we ask? Brain and Language, 98, 332-440.

Duñabeitia, J. A., Avilés, A., \& Carreiras, M. (2008). NoA's ark: Influence of the number of associates in visual word recognition. Psychonomic Bulletin \& Review, 15, 1072-1077. doi:10.3758/PBR. 15.6.1072

Fernandino, L., Conant, L., Binder, J. R., Blindauer, K., Hiner, B., Spangler, K., \& Desai, R. H. (2012). Parkinson's disease disrupts both automatic and controlled processing of action verbs. Brain and Language, 127, 65-74. doi:10.1016/j.bandl.2012.07.008

Fernandino, L., Conant, L., Binder, J. R., Blindauer, K., Hiner, B., Spangler, K., \& Desai, R. H. (2013). Where is the action? Action sentence processing in Parkinson's disease. Neuropsychologia, 51, 1510-1517. doi:10.1016/j.neuropsychologia.2013.04.008

Fischer, M. H., \& Zwaan, R. A. (2008). Embodied language: A review of the motor system in language comprehension. Quarterly Journal of Experimental Psychology, 6, 825-850.

Franklin, S., Howard, D., \& Patterson, K. (1995). Abstract word anomia. Cognitive Neuropsychology, 12, 549-566.

Gallese, V., \& Lakoff, G. (2005). The brain's concepts: The role of the sensory-motor system in reason and language. Cognitive Neuropsychology, 22, 455-479.

Garrard, P., \& Carroll, E. (2006). Lost in semantic space: A multi-modal, non-verbal assessment of feature knowledge in semantic dementia. Brain, 129, 1152-1163. doi:10.1093/brain/aw1069

Gianelli, C., Farnè, A., Salemme, R., Jeannerod, M., \& Roy, A. C. (2011). The agent is right: When motor embodied cognition is space-dependent. PLoS ONE, 6, e25036. doi:10.1371/journal.pone.0025036

Gibbs, R. W. (2006). Embodiment and cognitive science. New York, NY: Cambridge University Press.

Giesbrecht, B., Gamblin, C., \& Swaab, T. (2004). Separable effects of semantic priming and imageability on word processing in human cortex. Cerebral Cortex, 14, 521-529.
Glenberg, A. M., \& Gallese, V. (2012). Action-based language: A theory of language acquisition, comprehension, and production. Cortex, 48, 905-922.

Glenberg, A. M., \& Kaschak, M. P. (2002). Grounding language in action. Psychonomic Bulletin \& Review, 9, 558-565. doi:10.3758/ BF03196313

Glenberg, A. M., Sato, M., Cattaneo, L., Riggio, L., Palumbo, D., \& Buccino, G. (2008). Processing abstract language modulates motor system activity. Quarterly Journal of Experimental Psychology, 61, 905-919.

Goldberg, R. F., Perfetti, C. A., \& Schneider, W. (2006). Distinct and common cortical activations for multimodal semantic categories. Cognitive, Affective, \& Behavioral Neuroscience, 6, 214-222. doi: 10.3758/CABN.6.3.214

Gonzalez, J., Barros-Loscertales, A., Pulvermüller, F., Meseguer, V., Sanjuan, A., Belloch, V., \& Avila, C. (2006). Reading cinnamon activates olfactory brain regions. NeuroImage, 32, 906-912.

Goodglass, H., Hyde, M. R., \& Blumstein, S. (1969). Frequency, picturability and availability of nouns in aphasia. Cortex, 5, 104 119.

Grondin, R., Lupker, S. J., \& McRae, K. (2009). Shared features dominate semantic richness effects for concrete concepts. Journal of Memory and Language, 60, 1-19. doi:10.1016/j.jml.2008.09.001

Hargreaves, I. S., \& Pexman, P. M. (2012). Does richness lose its luster? Effects of extensive practice on semantic richness in visual word recognition. Frontiers in Human Neuroscience, 6(234), 1-11.

Harnad, S. (1990). The symbol grounding problem. Physica D, 42, 335346.

Hauk, O., Johnsrude, I., \& Pulvermüller, F. (2004). Somatotopic representation of action words in human motor and premotor cortex. Neuron, 41, 301-307.

Hodges, J., Bozeat, S., Lambon Ralph, M. A., Patterson, K., \& Spatt, J. (2000). The role of conceptual knowledge in object use evidence from semantic dementia. Brain, 123, 1913-1925.

Hodges, J. R., Graham, N., \& Patterson, K. (1995). Charting the progression in semantic dementia: Implications for the organisation of semantic memory. Memory, 3, 463-495.

Hoffman, P., \& Lambon Ralph, M. A. (2011). Reverse concreteness are not a typical feature of semantic dementia: Evidence for the huband-spoke model of conceptual representation. Cerebral Cortex, 21, 2103-2112.

Huang, H., Lee, C., \& Federmeier, K. D. (2010). Imagine that! ERPs provide evidence for distinct hemispheric contributions to the processing of concrete and abstract concepts. NeuroImage, 49, 1116-1123.

Hurley, S. (2008). The shared circuits model (SCM): How control, mirroring, simulation can enable imitation, deliberation, and mindreading. Behavioral and Brain Sciences, 31, 1-58.

Jefferies, E., \& Lambon Ralph, M. A. (2006). Semantic impairment in stroke aphasia versus semantic dementia: A case-series comparison. Brain, 129, 2132-2147.

Johnson-Frey, S. H. (2004). The neural bases of complex tool use in humans. Trends in Cognitive Sciences, 8, 71-78.

Kable, J. W., Kan, I. P., Wilson, A., Thompson-Schill, S. L., \& Chatterjee, A. (2005). Conceptual representations of action in lateral temporal cortex. Journal of Cognitive Neuroscience, 17, 855-870.

Kable, J. W., Lease-Spellmeyer, J., \& Chatterjee, A. (2002). Neural substrates of action event knowledge. Journal of Cognitive Neuroscience, 14, 795-805.

Kaschak, M. P., Madden, C. J., Therriault, D. J., Yaxley, R. H., Aveyard, M., Blanchard, A. A., \& Zwaan, R. A. (2005). Perception of motion affects language processing. Cognition, 94, B79-B89.

Katz, R. B., \& Goodglass, H. (1990). Deep dysphasia: Analysis of a rare form of repetition disorder. Brain and Language, 39, 153-185.

Kemmerer, D. (2010). How words capture visual experience: The perspective from cognitive neuroscience. In B. Malt \& P. Wolff (Eds.), 
Words and the world: How words capture human experience (pp. 289-329). Oxford, UK: Oxford University Press.

Kiefer, M., \& Pulvermüller, F. (2012). Conceptual representations in mind and brain: Theoretical developments, current evidence, and future directions. Cortex, 48, 805-825.

Kiefer, M., Sim, E.-J., Herrnberger, B., Grothe, J., \& Hoenig, K. (2008). The sound of concepts: Four markers for a link between auditory and conceptual brain systems. Journal of Neuroscience, 28, 12224 12230.

Kousta, S.-T., Vigliocco, G., Vinson, D. P., Andrews, M., \& Del Campo, E. (2011). The representation of abstract words: Why emotion matters. Journal of Experimental Psychology: General, 140, 14-34. doi:10.1037/a0021446

Kousta, S.-T., Vinson, D. P., \& Vigliocco, G. (2009). Emotion words, regardless of polarity, have processing advantage over neutral words. Cognition, 112, 473-481. doi:10.1016/j.cognition.2009.06. 007

Kurby, C. A., \& Zacks, J. M. (2013). The activity of modality-specific representations in naturalistic discourse processing. Brain and Language, 216, 338-349.

Lakoff, G. (1987). Women, fire, and dangerous things: What categories reveal about the mind. Chicago, IL: University of Chicago Press.

Lakoff, G., \& Johnson, M. (1980). Metaphors we live by. Chicago, IL: University of Chicago Press.

Lambon Ralph, M. A., McClelland, J. L., Patterson, K., Galton, C. J., \& Hodges, J. R. (2001). No right to speak? The relationship between object naming and semantic impairment: Neuropsychological evidence and a computational model. Journal of Cognitive Neuroscience, 13, 341-356. doi:10.1162/08989290151137395

Lambon Ralph, M. A., Pobric, G., \& Jefferies, E. (2009). Conceptual knowledge is underpinned by the temporal lobe bilaterally: Convergent evidence from rTMS. Cerebral Cortex, 19, 832-838. doi:10.1093/cercor/bhn131

Lambon Ralph, M. A., Sage, K., Jones, R. W., \& Mayberry, E. J. (2010). Coherent concepts are computed in the anterior temporal lobes. Proceedings of the National Academy of Sciences, 107, 27172722. doi:10.1073/pnas.0907307107

Lebois, L. A., Wilson-Mendenhall, C. D., \& Barsalou, L. W. (2014). Are automatic conceptual cores the gold standard of semantic processing? The context-dependence of spatial meaning in grounded congruency effects. Cognitive Science. Advance online publication. doi: 10.1111/cogs. 12174

Lehmann, D., Pascual-Marqui, R. D., Strik, W. K., \& Koenig, T. (2010). Core networks for visual-concrete and abstract thought content: A brain electric microstate analysis. Neurolmage, 49, 1073-1079. doi: 10.1016/j.neuroimage.2009.07.054

Louwerse, M. (2011). Symbol interdependency in symbolic and embodied cognition. Topics in Cognitive Science, 3, 273-302.

Louwerse, M., \& Jeuniaux, P. (2008). Language comprehension is both embodied and symbolic. In M. De Vega, A. M. Glenberg, \& A. C. Graesser (Eds.), Symbols, embodiment, and meaning (pp. 309-326). Oxford, UK: Oxford University Press.

Lynott, D., \& Connell, L. (2010). Embodied conceptual combination. Frontiers in Psychology, 1, 212.

Machery, E. (2007). Concept Empiricism: A methodological critique. Cognition, 104, 19-46.

Mahon, B. Z. (2015). What is embodied about cognition. Language, Cognition, and Neuroscience, 30, 420-429.

Mahon, B. Z., \& Caramazza, A. (2005). The orchestration of sensorymotor systems: Clues from neuropsychology. Cognitive Neuropsychology, 22, 480-494.

Mahon, B. Z., \& Caramazza, A. (2008). A critical look at the embodied cognition hypothesis and a new proposal for grounding conceptual content. Journal of Physiology, 102, 59-70. doi:10.1016/j. jphysparis.2008.03.004
Martin, N., \& Saffran, E. M. (1992). A computational account of deep dysphasia: Evidence from a single case study. Brain and Language, 43, 240-274.

McCaffrey, J. (2015). Reconceiving conceptual vehicles: Lessons from semantic dementia. Philosophical Psychology, 28, 337-354.

McCaffrey, J., \& Machery, E. (2012). Philosophical issues about concepts. Wiley Interdisciplinary Reviews: Cognitive Science, 3, 265279. doi:10.1002/wcs. 1166

Mellet, E., Tzourio, N., Denis, M., \& Mazoyer, B. (1998). Cortical anatomy of mental imagery of concrete nouns based on their dictionary definition. NeuroReport, 9, 803-808.

Meteyard, L., Bahrami, B., \& Vigliocco, G. (2007). Motion detection and motion verbs: Language affects low-level visual perception. Psychological Science, 18, 1007-1013.

Meteyard, L., Cuadrado, S. R., Bahrami, B., \& Vigliocco. (2012). Coming of age: A review of embodiment and the neuroscience of semantics. Cortex, 48, 788-804.

Moffat, M., Siakaluk, P. D., Sidhu, D. M., \& Pexman, P. M. (2015). Situated conceptualization and semantic processing: Effects of emotional experience and context availability in semantic categorization and naming tasks. Psychonomic Bulletin \& Review, 22, 408-419. doi:10.3758/s13423-014-0696-0

Newcombe, P. I., Campbell, C., Siakaluk, P. D., \& Pexman, P. M. (2012). Effects of emotional and sensorimotor knowledge in semantic processing of concrete and abstract nouns. Frontiers in Human Neuroscience, 6(275), 1-15.

Noppeney, U., \& Price, C. J. (2004). Retrieval of abstract semantics. NeuroImage, 22, 164-170.

Paivio, A. (1986). Mental representations: A dual coding approach. New York, NY: Oxford University Press.

Paivio, A. (2013). Dual coding theory, word abstractness, and emotion: A critical review of Kousta et al. (2011). Journal of Experimental Psychology: General, 142, 282-287.

Papagno, A., Fogliata, E., Catricalà, C., \& Miniussi. (2009). The lexical processing of abstract and concrete nouns. Brain Research, 1263, 78-86.

Papeo, L., Corradi-Dell'Acqua, C., \& Rumiati, R. I. (2011). "She" is not like "I": The tie between language and action is in our imagination. Journal of Cognitive Neuroscience, 23, 3939-3948.

Patterson, K., Graham, N., \& Hodges, J. R. (1994). The impact of semantic memory loss on phonological representations. Journal of Cognitive Neuroscience, 6, 57-69.

Patterson, K., Nestor, P. J., \& Rogers, T. T. (2007). Where do you know what you know? The representation of semantic knowledge in the human brain. Nature Reviews Neuroscience, 8, 976-987. doi:10. 1038/nrn2277

Pecher, D., Zeelenberg, R., \& Barsalou, L. W. (2003). Verifying properties from different modalities for concepts produces switching costs. Psychological Science, 14, 119-124. doi:10.1111/1467-9280.t01-101429

Pexman, P. M. (2012). Meaning-level influences on visual-word recognition. In J. S. Adelman (Ed.), Visual-word recognition: Vol. 2. Meaning and context, individuals and development (pp. 24-43). Hove, UK: Psychology Press.

Pexman, P. M., Hargreaves, I. S., Siakaluk, P. D., Bodner, G. E., \& Pope, J. (2008). There are many ways to be rich: Effects of three measures of semantic richness on visual word recognition. Psychonomic Bulletin \& Review, 15, 161-167. doi:10.3758/PBR.15.1.161

Pobric, G., Jefferies, E., \& Lambon Ralph, M. A. (2010). Amodal semantic representations depend on both left and right anterior temporal lobes: New rTMS evidence. Neuropsychologia, 48, 1336-1342.

Prinz, J. J. (2002). Furnishing the mind: Concepts and their perceptual basis. Cambridge, MA: MIT Press.

Pulvermüller, F. (2001). Brain reflections of words and their meaning. Trends in Cognitive Sciences, 5, 517-524. 
Pulvermüller, F., \& Garagnani, M. (2014). From sensorimotor learning to memory cells in prefrontal and temporal association cortex: A neurocomputational study of disembodiment. Cortex, 57, 1-21. doi:10.1016/j.cortex.2014.02.015

Pulvermüller, F., Hauk, O., Nikulin, V. V., \& Ilmoniemi, R. J. (2005). Functional links between motor and language systems. European Journal of Neuroscience, 21, 793-797. doi:10.1111/j.1460-9568. 2005.03900.x

Raposo, A., Moss, H. E., Stamatakis, E. A., \& Tyler, L. K. (2009). Modulation of motor and premotor cortices by actions, action words and action sentences. Neuropsychologia, 47, 388-396.

Reilly, J., Cross, K., Troiani, V., \& Grossman, M. (2007). Single word semantic judgments in semantic dementia: Do phonology and grammatical class count? Aphasiology, 21, 558-569.

Reilly, J., Harnish, S., Garcia, A., Hung, J., Rodriguez, A. D., \& Crosson, B. (2014). Lesion symptom mapping in nonfluent aphasia: Can a brain be both embodied and disembodied? Cognitive Neuropsychology, 31, 287-312.

Reilly, J., \& Peelle, J. E. (2008). Effects of semantic impairment on language processing in semantic dementia. Seminars in Speech and Language, 29, 32-43.

Reilly, J., Rodriguez, A., Peelle, J. E., \& Grossman, M. (2011). Frontal lobe damage impairs process and content in semantic memory: Evidence from category specific effects in progressive nonfluent aphasia. Cortex, 47, 645-658.

Richardson, D. C., Spivey, M. J., Barsalou, L. W., \& McRae, K. (2003). Spatial representations activated during real-time comprehension of verbs. Cognitive Science, 27, 767-780. doi:10.1207/ s15516709 $\operatorname{cog} 27054$

Riordan, B., \& Jones, M. N. (2010). Redundancy in perceptual and linguistic experience: Comparing feature-based and distributional models of semantic information. Topics in Cognitive Science, 3, 303-345.

Rosch, E. (1978). Principles of categorization. In E. Rosch \& B. B. Lloyd (Eds.), Cognition and categorization (pp. 28-49). Hillsdale, NJ: Erlbaum.

Sabsevitz, D., Medler, D., Seidenberg, M., \& Binder, J. (2005). Modulation of the semantic system by word imageability. NeuroImage, 27, 188-200.

Sakreida, K., Scorolli, C., Menz, M. M., Heim, S., Borghi, A. M., \& Binkofski, F. (2013). Are abstract action words embodied? An fMRI investigation at the interface between language and motor cognition. Frontiers in Human Neuroscience, 7(125), 1-13. doi: 10.3389/fnhum.2013.00125

Saygin, A. P., McCullough, S., Alac, M., \& Emmorey, K. (2010). Modulation of BOLD response in motion-sensitive lateral temporal cortex by real and fictive motion sentences. Journal of Cognitive Neuroscience, 22, 2480-2490.

Schwanenflugel, P. J., \& Shoben, E. J. (1983). Differential context effects in the comprehension of abstract and concrete verbal materials. Journal of Experimental Psychology: Learning, Memory, and Cognition, 9, 82-102. doi:10.1037/0278-7393.9.1.82

Scorolli, C., Binkofski, F., Buccino, G., Nicoletti, R., Riggio, L., \& Borghi, A. (2011). Abstract and concrete sentences, embodiment and languages. Frontiers in Psychology, 2, 227.

Scorolli, C., Jacquet, P. O., Binkofski, F., Nicoletti, R., Tessari, A., \& Borghi, A. (2012). Abstract and concrete phrases processing differently modulates cortico-spinal excitability. Brain Research, 1488, $60-71$.

Shallice, T., \& Cooper, R. (2013). Is there a semantic system for abstract words? Frontiers in Human Neuroscience, 7(175), 1-10. doi:10. 3389/fnhum.2013.00175

Shallice, T., \& Warrington, E. K. (1975). Word recognition in a phonemic dyslexic patient. Quarterly Journal of Experimental Psychology, 27, 187-199.
Siakaluk, P. D., Knol, N., \& Pexman, P. M. (2014). Effects of emotional experience for abstract words in the Stroop task. Cognitive Science, 38, 1698-1717. doi:10.1111/cogs.12137

Siakaluk, P. D., Pexman, P. M., Sears, C. R., Wilson, K., Locheed, K., \& Owen, W. J. (2008). The benefits of sensorimotor knowledge: Bodyobject interaction facilitates semantic processing. Cognitive Science, 32, 591-605.

Simmons, K. W., \& Barsalou, L. W. (2003). The similarity-in-topography principle: Reconciling theories of conceptual deficits. Cognitive Neuropsychology, 20, 451-486.

Simmons, W. K., Ramjee, V., Beauchamp, M. S., McRae, K., Martin, A., \& Barsalou, L. W. (2007). A common neural substrate for perceiving and knowing about color. Neuropsychologia, 45, 2802-2810.

Stramandinoli, F., Marocco, D., \& Cangelosi, A. (2012). The grounding of higher order concepts in action and language: A cognitive robotics model. Neural Networks, 32, 165-173.

Tettamanti, M., Buccino, G., Saccuman, M., Gallese, V., Danna, M., Scifo, P., ... Perani, D. (2005). Listening to action-related sentences activates fronto-parietal motor circuits. Journal of Cognitive Neuroscience, 17, 273-281.

Thill, S., Pado, S., \& Ziemke, T. (2014). On the importance of rich grounding of concepts: Perspectives from embodied cognitive science and computational linguistics. Topics in Cognitive Science, 6 , $545-558$.

Troche, J., Crutch, S., \& Reilly, J. (2014). Clustering, hierarchical organization, and the topography of abstract and concrete nouns. Frontiers in Psychology, 5(360), 1-10.

Trumpp, N. M., Kliese, D., Hoenig, K., Haarmeier, T., \& Kiefer, M. (2013). Losing the sound of concepts: Damage to the auditory association cortex impairs the processing of sound-related concepts. Cortex, 49, 474-486. doi:10.1016/j.cortex.2012.02.002

van Dantzig, S., Pecher, D., Zeelenberg, R., \& Barsalou, L. W. (2008). Perceptual processing affects conceptual processing. Cognitive Science, 32, 579-590.

Vigliocco, G., Kousta, S. T., Della Rosa, P. A., Vinson, D. P., Tettamanti, M., Devlin, J. T., \& Cappa, S. F. (2014). The neural representation of abstract words: The role of emotion. Cerebral Cortex, 24, 17671777.

Vigliocco, G., Meteyard, L., Andrews, M., \& Kousta, S. (2009). Toward a theory of semantic representation. Language and Cognition, 1, 219 247.

Vigliocco, G., Vinson, D. P., Druks, J., Barber, H., \& Cappa, S. F. (2011). Nouns and verbs in the brain: A review of behavioural, electrophysiological, neurophysiological and imaging studies. Neuroscience \& Biobehavioral Reviews, 35, 407-426. doi:10.1016/j.neubiorev. 2010.04.007

Vigliocco, G., Vinson, D. P., Lewis, W., \& Garrett, M. F. (2004). Representing meanings of object and action words: The featural and unitary semantic space hypothesis. Cognitive Psychology, 48, 422-488. doi:10.1016/j.cogpsych.2003.09.001

Vygotsky, L. (2012). Thought and language (Rev. and exp. ed.). Cambridge, MA: MIT Press.

Wang, J., Conder, J. A., Blitzer, D. N., \& Shinkareva, S. V. (2010). Neural representation of abstract and concrete concepts: A meta-analysis of imaging studies. Human Brain Mapping, 31, 1459-1468.

Watson, C. E., Cardillo, E. R., Ianni, G. R., \& Chatterjee, A. (2013). Action concepts in the brain: An activation likelihood estimation meta-analysis. Journal of Cognitive Neuroscience, 25, 1191-1205.

Watson, C. E., \& Chatterjee, A. (2011). The functional neuroanatomy of actions. Neurology, 76, 1428-1434.

Wattenmaker, W., \& Shoben, E. (1987). Context and the recallability of concrete and abstract sentences. Journal of Experimental Psychology, 13, 140-150.

Weiskopf, D. (2007). Concept empiricism and the vehicles of thought. Journal of Consciousness Studies, 14, 156-183. 
Wellsby, M., \& Pexman, P. M. (2014). Developing embodied cognition: Insights from children's concepts and language processing. Frontiers in Psychology, 5, 506. doi:10.3389/fpsyg.2014.00506

Wellsby, M., Siakaluk, P. D., Owen, W. J., \& Pexman, P. M. (2011). Embodied semantic processing: The body-object interaction effect in a non-manual task. Language and Cognition, 3, 1-14.

Willems, R. M., \& Casasanto, D. (2011). Flexibility in embodied understanding. Frontiers in Psychology, 2, 116. doi:10.3389/fpsyg.2011. 00116

Willems, R. M., \& Francken, J. C. (2012). Embodied cognition: Taking the next step. Frontiers in Psychology, 3, 582.

Willems, R. M., Hagoort, P., \& Casasanto, D. (2010). Body-specific representation of action words: Neural evidence from right- and left-handers. Psychological Science, 21, 67-74.

Wilson, M. (2002). Six views of embodied cognition. Psychonomic Bulletin \& Review, 9, 625-636. doi:10.3758/BF03196322

Wilson, A. D., \& Golonka, S. (2013). Embodied cognition is not what you think it is. Frontiers in Psychology, 4, 58. doi:10.3389/fpsyg. 2013.00058
Wilson-Mendenhall, C. D., Simmons, W. K., Martin, A., \& Barsalou, L. W. (2013). Contextual processing of abstract concepts reveals neural representations of non-linguistic semantic content. Journal of Cognitive Neuroscience, 25, 920-935.

Yap, M. J., Pexman, P. M., Wellsby, M., Hargreaves, I. S., \& Huff, M. (2012). An abundance of riches: Cross-task comparison of semantic richness effects in visual word recognition. Frontiers in Human Neuroscience, 6(72), 1-10. doi:10.3389/fnhum.2012.00072

Yi, H.-A., Moore, P., \& Grossman, M. (2007). Reversal of the concreteness effect for verbs in patients with semantic dementia. Neuropsychology, 21, 9-19. doi:10.1037/0894-4105.21.1.9

Zdrazilova, L., \& Pexman, P. M. (2013). Grasping the invisible: Semantic processing of abstract words. Psychonomic Bulletin \& Review, 20, 1312-1318. doi:10.3758/s13423-013-0452-x

Zwaan, R. A. (2014). Embodiment and language comprehension: Reframing the discussion. Trends in Cognitive Sciences, 18, 229234. 